\title{
CONSERVADORISMO CONTÁBIL E TIMELINESS: EVIDÊNCIAS EMPÍRICAS NAS DEMONSTRAÇÕES CONTÁBEIS DE EMPRESAS BRASILEIRAS COM ADRS NEGOCIADOS NA BOLSA DE NOVA IORQUE
}

ACCOUNTING CONSERVATISM AND TIMELINESS: EMPIRICAL EVIDENCE IN FINANCIAL STATEMENTS OF BRAZILIAN COMPANIES WITH ADRS TRADED ON THE NEW YORK STOCK EXCHANGE

\author{
LUIS SÉRGIO RIBEIRO DOS SANTOS \\ Professor Mestre em Ciências Contábeis do Departamento de Contabilidade e \\ Administração das Faculdades FASERRA/FABAVI/FACELI \\ E-mail: Isrsantos@mcorcovado.com.br
}

FÁBIO MORAES DA COSTA

Professor Associado da Fucape Business School E-mail: fabio@fucape.br

\section{RESUMO}

Este estudo investiga o nível de utilização do conservadorismo e da oportunidade (timeliness) da informação contábil nas demonstrações contábeis de empresas brasileiras com ADRs negociados na Bolsa de Nova Iorque. Essas empresas apresentam suas demonstrações contábeis tanto conforme o modelo contábil brasileiro quanto segundo o norte-americano, atendendo às exigências da Securities and Exchange Commission (SEC). Os dados foram coletados compreendendo o período de 1999 a 2004 e aplicou-se o modelo de Basu (BASU, 1997) para a avaliação da oportunidade e do conservadorismo da informação contábil. Os resultados encontrados indicam que (1) não hả diferenças no nível de utilização do conservadorismo e (2) o lucro contábil segundo o modelo brasileiro seria mais oportuno do que o norte-americano. Assim, as evidências contribuem para o atual debate sobre a inserção do Brasil no atual estágio de convergência de demonstrações contábeis.

Palavras-chave: Conservadorismo. Oportunidade. Contabilidade Internacional. Processo de Convergência.

\section{ABSTRACT}

This study investigates the timeliness and the degree of conservatism in financial statements disclosed by Brazilian companies with ADRs traded on the New York Stock Exchange. According to the Securities and Exchange Commission (SEC), those companies must disclose accounting information according to the Brazilian Generally Accepted Accounting Principles (BR GAAP) as well as the United States Generally Accepted Accounting Principles (US GAAP). The data were collected between 1999 and 2004 and the Basu Model (BASU, 1997) was applied to evaluate earnings timeliness and conservatism. The results are: (1) there is no difference in earnings conservatism and (2) earnings according to the $B R$ GAAP are more timely than those according to the US GAAP. The evidence contributes to the current debate about the role of Brazil in the current stage of the convergenice process.

Keywords: Conservatism. Timeliness. International Accounting. Convergence Process. 


\section{INTRODUÇÃO}

Atualmente, os usuários da informação contábil acompanham o processo de convergência de normas, tendo como foco a adoção ou recomendação de uso por cerca de 100 países aos International Financial Reporting Standards (IFRS) emitidos pelo International Accounting Standards Board (IASB).

Além disso, após a assinatura do Norwalk Agreement, em 2002, o IASB e o Financial Accounting Standards Board (FASB) norte-americano têm reduzido as diferenças de tratamento contábil para os mesmos eventos econômicos. Haverty (2004) apresenta resultados de que, ao longo do tempo, os IFRS e United States Generally Accepted Accounting Principles (US GAAP) têm se aproximado, cujo efeito levaria ao conteúdo informacional cada vez mais similar das demonstrações contábeis divulgadas pelos dois modelos (LEUZ, 2003).

No Brasil, a migração para o modelo contábil internacional foi intensificada após decisões da Comissão de Valores Mobiliários (CVM) e do Banco Central do Brasil, além da promulgação da Lei 11.638/2007. Novos pronunciamentos contábeis emitidos são similares aos IFRS, os quais, em sua maioria, são similares em termos de princípios aos US GAAP.

Além desse fato, recentemente a Securities and Exchange Commission (SEC) passou a permitir que empresas com American Depositary Receipts (ADRs) negociados na Bolsa de Nova lorque divulguem informações contábeis em IFRS sem a necessidade de reconciliação para os US GAAP.

O processo de convergência e a decisão da SEC levam ao questionamento sobre a hipótese de que a adoção de um novo modelo contábil proveria ao mercado informações mais relevantes e confiáveis para a tomada de decisão de seus usuários em relação à alocação mais eficiente de seus recursos. Tal fato estaria ligado a características institucionais do país, as quais desempenham papel fundamental na qualidade da informação contábil divulgada (BALL et al., 2000).

Segundo Costa (2005), a atual discussão sobre adoção de pronunciamentos contábeis internacionais no Brasil suscitaria questionamento sobre sua relevância ou não para os usuários do mercado de capitais. Como ainda há um reduzido número de companhias brasileiras que publicam suas demonstrações segundo os IFRS, o autor utiliza como proxy para tais efeitos aquelas elaboradas segundo OS US GAAP.

Utilizando uma amostra composta por companhias brasileiras com ADRs (American Depositary Receipts) negociados na Bolsa de Nova lorque, Costa (2005) conclui que apenas os ajustes efetuados ao patrimônio líquido para atender aos US GAAP seriam relevantes, justificando que fatores como estrutura de governança corporativa, a alta concentração acionária, a orientação para credores e a antecipação de informações segundo os Princípios de Con- tabilidade Geralmente Aceitos (PCGAs) no Brasil seriam possíveis explicações para seus resultados.

Na mesma linha de pesquisas, Tukamoto (2004), também utilizando como amostra companhias brasileiras com ADRs, apresentou evidências de que o nível de gerenciamento de resultados das demonstrações contábeis elaboradas segundo os PCGAs brasileiros seria similar aos US GAAP.

Visando contribuir para as evidências encontradas no Brasil, este trabalho busca avaliar duas outras características da informação contábil: conservadorismo e oportunidade. Assim, seria permitido avaliar e comparar a qualidade da informação contábil entre modelos distintos (PCGAs brasileiros e US GAAP) utilizados pelo mesmo grupo de empresas.

Nesse contexto, a oportunidade da informação contábil é entendida como o grau de associação entre o comportamento dos investidores de mercado, medido pelo retorno da ação no período e o resultado contábil divulgado (BUSHMAN et al., 2004). Assim, espera-se que quanto maior o grau de associação, mais oportuna seria a informação contábil no sentido de refletir as expectativas dos agentes no mercado.

Por sua vez, o conservadorismo contábil consiste no reconhecimento assimétrico entre o grau de verificabilidade exigido para o reconhecimento de receitas e ativos em comparação ao reconhecimento de despesas e passivos (WATTS, 2003). Como conseqüência, o resultado contábil seria mais oportuno para reconhecer "más notícias" do que "boas notícias" (WATTS, 2003).

Especificamente, o presente estudo visa investigar empiricamente se o nível de conservadorismo contábil nas demonstrações elaboradas segundo os US GAAP por empresas brasileiras é diferente daquelas segundo os PCGAs brasileiros. De forma complementar à investigação do reconhecimento assimétrico entre "boas notícias" e "más notícias", será avaliado o grau de associação entre a informação contábil e o comportamento de preços no mercado, ou seja, sua oportunidade.

A questão de pesquisa, portanto, consiste na avaliação sobre qual o nível de utilização do conservadorismo e como o resultado contábil está associado ao retorno econômico da ação em relação às demonstrações contábeis elaboradas segundo os PCGAs brasileiros e US GAAP de companhias brasileiras com ADRs negociados na Bolsa de Nova lorque.

Em sentido amplo, procura-se contribuir para o entendimento sobre o comportamento da informação contábil e seu papel de intermediária informacional para auxiliar na tomada de decisão de analistas de mercado e de atuais e potenciais investidores. 


\section{A CAPACIDADE INFORMACIONAL DA CONTABILIDADE}

A relação entre o resultado contábil e o comportamento de variáveis de mercado tem sido objeto da área de pesquisas em contabilidade desde o final da década de 60, após os trabalhos considerados seminais de Ball e Brown (1968) e de Beaver (1968). Ambos os trabalhos evidenciam que as variáveis contábeis possuem conteúdo informacional relevante para os usuários pertencentes ao mercado de capitais.

Uma das razões para a relevância da informação contábil para o usuário externo recai sobre sua capacidade de redução da assimetria informacional. Akerlof (1970) demonstra que em um cenário de assimetria informacional máxima, o preço não auxiliaria na distinção sobre o melhor investimento a ser feito, o que poderia gerar, inclusive, problemas relacionados à seleção adversa.

No Brasil, Sarlo Neto (2004) investigou se as informações contidas nas demonstrações contábeis e divulgadas ao mercado estariam refletidas nos preços das ações, demonstrando a utilidade do modelo contábil. Os resultados encontrados são similares aos de Ball e Brown (1968) citados anteriormente.

Por outro lado, conforme as evidências de Lopes (2001), o resultado contábil é pouco oportuno para o mercado. O autor justifica que a alta concentração acionária no Brasil seria um dos fatores de redução da capacidade informacional dos resultados, pois parte significativa da informação contábil já seria conhecida pelos acionistas majoritários; assim, a redução de assimetria informacional seria resolvida, em grande parte, de maneira privada.

Além disso, como a principal fonte de financiamento das companhias brasileiras é realizada via credores, o pa- trimônio líquido teria maior relevância por causa de restrições impostas em contratos (covenants) e por ser uma proxy para o valor de liquidação da companhia (LOPES, 2001; COSTA, 2005).

As características apresentadas nos dois parágrafos anteriores são comuns a países classificados como code-law (LA PORTA et al., 1998). Em contraponto, países como Estados Unidos, Inglaterra e Austrália, com companhias cujo controle acionário é pulverizado e o financiamento ocorre via captações no mercado de capitais, seriam considerados como common-law.

Em relação à oportunidade da informação contábil, Ball, Kothari e Robin (2000) apresentam evidências de que o resultado contábil é mais oportuno em países common-law.

Costa (2005) avaliou a relevância das informações contábeis ajustadas aos US GAAP realizados por empresas brasileiras que possuem ADRs negociados na Bolsa de Nova lorque, e os resultados encontrados evidenciam que a informação contábil é relevante, mas que as informações em US GAAP possuem conteúdo informacional já existente e os ajustes aos US GAAP são relevantes para o mercado apenas em relação ao patrimônio líquido, mas não no tocante ao lucro líquido.

Assim, em relação à oportunidade do resultado contábil elaborada segundo os US GAAP, espera-se uma baixa associação entre essa e o retorno das ações no período, pois mesmo as empresas que possuem ADRs negociados na Bolsa de Nova lorque possuem controle acionário concentrado (COSTA, 2005).

troski (2005). O modelo desenvolvido por Basu (1997) é freqüentemente apontado como o mais utilizado para avaliar o grau de conservadorismo do resultado contábil (WATTS, 2003).

Basu (1997) apresenta evidências empíricas de que o resultado contábil apresenta maior associação com retornos negativos da ação ("más notícias") se comparado a retornos positivos ("boas notícias"). Sua amostra compreendeu dados de companhias com títulos negociados na Bolsa de Nova lorque entre 1963 a 1990.

Os resultados encontrados no estudo de Basu (1997), além de demonstrarem que os retornos refletem mais rapidamente as notícias ruins do que as boas e os testes também revelam que o nível de utilização do conservadorismo pode ter aumentado nos últimos anos, esses aumentos do conservadorismo coincidem com o aumento do custo de litígios e da responsabilidade legal dos auditores, o que geraria incentivo à divulgação de demonstrações contábeis "conservadoras".

Ball, Kothari e Robim (2000) estudaram o conservadorismo utilizando o modelo de Basu (1997) nos países code(1993, 2003), Penman e Zhang (1999), Bushman e Pio- 
law e common-law, confirmando a hipótese de que o lucro contábil é mais constante e menos oportuno nos países code-law. Confirmaram, também, que o conservadorismo é uma medida presente no lucro contábil em todos os países pesquisados.

A utilização do conservadorismo gerou críticas por parte de alguns pesquisadores, como exemplo, o trabalho de Penman e Zhang (1999).

Penman e Zhang (1999) propuseram-se a estudar o conservadorismo e o seu efeito na qualidade do lucro na visão dos analistas de mercado e alertam que o conservadorismo contábil pode gerar lucros de baixa qualidade. Outros autores, como Hendriksen e Breda (1999), também criticam o conservadorismo justificando que essa prática contábil conflita com o objetivo da contabilidade de divulgar toda informação relevante.

Em contraponto, Watts (2003) argumenta que o conservadorismo seria necessário, exercendo a função de mitigar comportamentos oportunísticos de gestores, auxiliar no acompanhamento de covenants por credores, além de ser incentivado em ambientes institucionais com maiores custos de litígios.

O sistema jurídico dos países pode impactar na qualidade das informações contábeis. Segundo Bushman e Piotroski (2005), as empresas nos países com sistemas judiciais fortes refletem as más notícias mais rápido que empresas em países com sistemas judiciais fracos.
Na literatura acadêmica brasileira, encontram-se recentes estudos sobre o efeito do conservadorismo contábil. Costa, Lopes e Costa (2006), por exemplo, pesquisaram a aplicação do conservadorismo contábil e a oportunidade da informação contábil utilizando o modelo de Basu (1997) em cinco países da América do Sul (Argentina, Brasil, Colômbia, Peru e Venezuela).

Os resultados encontrados pela autora evidenciam a baixa relação entre lucro corrente e retorno corrente, indicando que nesses países, devido à relação entre modelos de governança corporativa e relevância da informação contábil, em conjunto com o ambiente institucional, a contabilidade não incorpora tão significativamente o retorno econômico como nos países commom-law.

Apesar da baixa relação entre lucro e retorno, Costa, Lopes e Costa (2004) constataram que o reconhecimento dos resultados negativos é maior que o reconhecimento do retorno como um todo, evidenciando conservadorismo nos resultados contábeis.

Corroborando os estudos sobre conservadorismo no Brasil, Lopes (2001) conclui que,

a característica de conservadorismo dos dados brasileiros são consistentes com os primeiros resultados e com a literatura de governança corporativa mostrando que uma ligação entre relevância da informação contábil e a estrutura geral de governança corporativa é uma alternativa promissora de pesquisa.

\section{HIPÓTESES DO TRABALHO}

Atendendo a perspectiva de que a regulamentação contábil (US GAAP e BR GAAP) pode interferir na utilização do conservadorismo e na oportunidade do lucro contábil, esta pesquisa apresenta as seguintes hipóteses a serem testadas nas empresas listadas na Bovespa emissoras de ADRs para as ações preferenciais e ordinárias:

\section{$\mathrm{H}_{0 \mathrm{a}}$ : As demonstrações elaboradas segundo os US GAAP são mais conservadoras que as demonstrações elaboradas segundo os PCGAs brasileiros.}

A primeira hipótese elaborada procura comparar o nível de utilização do conservadorismo entre os GAAPs, com o objetivo de apontar evidências de que a norma contábil americana seria ou não mais conservadora que a norma contábil brasileira, tanto para as ações preferenciais quanto para as ações ordinárias. Conforme discutido no capítulo 2, existem várias diferenças na norma contábil entre o padrão brasileiro e o americano. Encontra-se na literatura internacional estudo realizado por Pope e Walker (1999), que, ao investigar o GAAP americano e o GAAP inglês, encontraram evidências de que o conservadorismo é utilizado de maneira diferente, sendo maior nas empresas americanas.

$H_{0 b}:$ O lucro contábil em US GAAP incorpora
mais significativamente o retorno econô-

\section{mico (timeliness) que o lucro contábil em BR GAAP.}

A segunda hipótese elaborada refere-se à oportunidade do lucro segundo o lucro contábil na norma brasileira e americana para os retornos de abril e junho, respectivamente. Essa hipótese procura levantar evidências sobre a oportunidade da informação contábil entre os GAAPs brasileiro e americano para as empresas brasileiras. Pode-se encontrar, na literatura, pesquisas que evidenciaram uma baixa relação entre o lucro contábil e retorno econômico em países code-law, como exemplo o estudo de Ball, Kothari e Robim (1999). Entretanto, essa relação foi estabelecida entre o retorno e o lucro segundo as normas do país origem.

\section{$H_{o c}: A$ parcela não explicada pelo lucro contábil em BR GAAP incorpora o retorno econômico (timeliness) de junho e o reconhecimento as- simétrico entre boas e más noticias.}

A terceira hipótese foi estruturada com objetivo de levantar evidências de que os ajustes realizados no lucro em BR GAAP para obter as demonstrações contábeis em US GAAP incorporam o conservadorismo e a oportunidade da informação contábil. Costa (2005) investigou a relevância dos ajustes aos US GAAP nas 
empresas emissoras de ADR e seus resultados identificaram que os ajustes são relevantes para o mercado em relação ao patrimônio líquido, mas não no tocante ao lucro líquido.

\section{O MODELO}

O modelo utilizado será o mesmo desenvolvido por Basu (1997) e aplicado para companhias brasileiras por Costa, Lopes e Costa (2006). O modelo de Basu (1997) permite estudar as variáveis lucro, retorno, boas e más notícias. Conforme apresentado por Costa, Lopes e Costa (2006), o modelo é dado com as seguintes expressões:

$$
\frac{L u c_{i t}}{P_{i t-1}}=\alpha_{0}+\alpha_{1} D_{i t}+\alpha_{2} \frac{R E_{i t}}{P_{i t-1}}+\alpha_{3} D_{i t} \frac{R E_{i t}}{P_{i t-1}}+\varepsilon_{i t}
$$

em que:

$$
\begin{aligned}
L u c_{i t}= & \text { Lucro líquido (contábil) por ação da empresa i } \\
& \text { no ano t. } \\
D_{i t}= & \text { Variável dummy, que será } 1 \text { se o retorno eco- } \\
& \text { nômico for negativo e zero nos demais casos. } \\
R E_{i t}= & \begin{array}{l}
\text { Retorno econômico por ação da empresa i no } \\
\text { ano } t\left(P_{i t}-P_{i t-1}\right. \text { ajustado pelo pagamento de } \\
\text { dividendos). }
\end{array} \\
P_{i t-1}= & \begin{array}{l}
\text { Preço da ação da empresa i no final do ano an- } \\
\text { terior. }
\end{array} \\
\alpha_{2}= & \begin{array}{l}
\text { Reflete a oportunidade do lucro contábil, ou } \\
\text { seja, o reconhecimento do retorno econômico }
\end{array} \\
& \text { pelo lucro contábil. } \\
\alpha_{1} \text { e } \alpha_{3}= & \text { Refletem o reconhecimento assimétrico do re- } \\
& \text { torno econômico às boas e más notícias, pelo } \\
& \text { lucro contábil. } \\
\varepsilon_{i t}= & \text { Termo de erro da regressão. }
\end{aligned}
$$

\section{COLETA E TRATAMENTO DE DADOS}

A população pesquisada, neste trabalho, consiste nas empresas abertas que emitiram ADRs listadas na Bovespa. O período pesquisado para coleta de dados foi de dezembro de 1992 até junho de 2004. Apesar da primeira emissão de ADR ser registrada em 1992 na Bolsa de Nova lorque, optou-se por utilizar o período compreendido entre 1999 a 2004 em função do reduzido número de observações anteriores a esse período.

Identifica-se, no período pesquisado, um total de $35 \mathrm{em}$ presas brasileiras que negociaram ADRs na Bolsa de Nova lorque. Da amostra inicial, foram excluídas as companhias Gol Linhas Aéreas Inteligentes S.A e CPFL Energia S.A por terem emitido ADRs no exercício de 2004. Portanto, não foi possível obter suas informações em US GAAP, resultando na amostra final composta por 33 companhias brasileiras.

As variáveis exigidas no modelo utilizado na pesquisa (modelo de Basu 1997), que são lucro líquido contábil por ação, retorno econômico e preço das ações, foram retiradas da Bovespa, para as informações contábeis em BR GAAP e da Bolsa de Nova lorque, para as informações contábeis em US GAAP.
De acordo com Basu (1997), a variável dummy é utilizada para verificar se o lucro contábil é mais sensível aos resultados negativos que aos positivos. O coeficiente $\alpha_{2}$ reflete o reconhecimento do retorno econômico pelo lucro tanto positivo quanto negativo, enquanto $\alpha_{3}$ somente 0 resultado negativo.

Os parâmetros da regressão $\alpha_{1}$ e $\alpha_{3}$ são definidos como os coeficientes que refletem o reconhecimento assimétrico do retorno econômico pelo lucro contábil, ou seja, os coeficientes $\alpha_{1}$ e $\alpha_{3}$ refletem o conservadorismo.

Espera-se, no modelo, que o coeficiente $\alpha_{3}$, ao capturar o reconhecimento assimétrico entre boas e más notícias, apresentará sinal positivo. O coeficiente positivo de $\alpha_{3}$ demonstra que o resultado contábil reflete mais oportunamente retornos negativos do que positivos; ou seja, há conservadorismo.

Conforme critério utilizado por Basu (1997), as variáveis contábeis são deflacionadas pelo preço da ação do final do ano anterior $\left(P_{i t-1}\right)$ para controle da heterocedasticidade e do efeito escala.
Para obtenção dos dados em BR GAAP, foi utilizado o software Economática, e para obtenção dos dados em US GAAP, eles foram extraídos diretamente dos Relatórios 20-F depositados na SEC.

Para atender aos objetivos da pesquisa e à composição acionária do mercado brasileiro, optou-se por dividir a base de dados em ações preferenciais e ordinárias. A justificativa em subdividir a amostra em ações preferenciais e ações ordinárias deve-se ao fato de que o acionista pode possuir diferentes interesses (controle ou dividendos), podendo a informação contábil impactar de maneira diferente. Devido a esse comportamento, Sarlo Neto (2004) sugere que, ao relacionar as variáveis lucro e retorno, as amostras sejam subdivididas em ações preferenciais e ordinárias.

Para testar a terceira hipótese desta pesquisa serão utilizados os resíduos da regressão entre lucro contábil em US GAAP e lucro contábil em BR GAAP como proxies para os ajustes realizados no lucro contábil brasileiro segundo as normas americanas. Costa (2005) utiliza essa métrica para medir os ajustes aos US GAAP. 
A escolha por utilizar a variável retorno de 4 meses após o encerramento do exercício social para o lucro brasileiro e de 6 meses para o lucro americano tem como objetivo assegurar a resposta do mercado para os retornos do fim do ano fiscal, ou seja, a oportunidade da informação. Esse procedimento foi o mesmo adotado por Basu (1997).

Optou-se por utilizar a metodologia de dados em painel, que permite capturar o comportamento das variáveis tanto na dimensão temporal quanto na espacial.

Após todos os procedimentos adotados para obtenção de dados, as amostras apresentam 118 observações para as ações preferenciais e 110 observações para as ações ordinárias.

A aplicação do modelo de dados em painel permite a consideração de efeitos constantes, fixos e aleatórios, de- vendo-se adotar um teste estatístico para a definição daquele a ser utilizado. Os testes utilizados para a escolha foram os de Breusch e Pagan (1980) e Hausman (1978), resultando na escolha por efeitos fixos.

De posse dos dados extraídos, foram levantadas as seguintes estatísticas descritivas sobre as principais variáveis do modelo (Quadro 1 ( ) .

Observando a estatística descritiva das variáveis envolvidas na pesquisa pode-se refletir sobre importantes informações. A relação entre a média e desvio-padrão evidenciam um cenário de alta volatilidade em decorrência do mercado de capitais brasileiro e do ambiente econômico. Essas informações corroboram os achados no trabalho de Sarlo Neto (2004).

\section{ANÁLISE DOS RESULTADOS}

A Tabela 20 apresenta os resultados das regressões estatísticas para o conservadorismo e a oportunidade do lucro contábil segundo as normas contábeis brasileiras.

A Tabela 2 indica que o lucro líquido, na norma contábil brasileira, incorpora, significativamente, o retorno econômico de abril, em que o coeficiente $\alpha_{2}$, que mede a oportunidade do lucro, é positivo e estatisticamente significante ao nível de $10 \%$ para as ações preferenciais e $1 \%$ para as ações ordinárias. O coeficiente $\alpha_{2}$ positivo revela uma relação direta entre lucro e retorno. Analisando as

\begin{tabular}{|l|c|c|c|c|c|c|c|c|c|c|}
\hline \multirow{2}{*}{ Estatística } & \multicolumn{2}{|c|}{ Lucro BR GAAP } & \multicolumn{2}{c|}{ Lucro US GAAP } & \multicolumn{2}{c|}{ Retorno abril } & \multicolumn{2}{c|}{ Retorno junho } & \multicolumn{2}{c|}{ Resíduo } \\
\cline { 2 - 12 } & PN & ON & PN & ON & PN & ON & PN & ON & PN & ON \\
Média & 0.113 & 0.121 & 0.107 & 0.123 & 0.096 & 0.185 & 0.113 & 0.128 & 0.002 & 0.006 \\
\hline Mediana & 0.065 & 0.076 & 0.069 & 0.078 & -0.068 & -0.041 & -0.017 & 0.027 & 0.002 & 0.013 \\
\hline Máximo & 2.856 & 1.904 & 1.819 & 3.637 & 4.196 & 7.458 & 2.182 & 2.113 & 0.909 & 1.447 \\
\hline Mínimo & -0.912 & -0.972 & -1.610 & -1.716 & 0.999 & -0.999 & -0.999 & -0.999 & -0.980 & -1.610 \\
\hline Desvio-padrão & 0.319 & 0.291 & 0.327 & 0.444 & 0.666 & 0.931 & 0.587 & 0.550 & 0.206 & 0.240 \\
\hline
\end{tabular}

Quadro 1 Estatística Descritiva

Tabela 2 Regressões para lucro contábil segundo as normas brasileiras

$$
\frac{L u c_{i t}}{P_{i t-1}}=\alpha_{0}+\alpha_{1} D_{i t}+\alpha_{2} \frac{R E_{i t}}{P_{i t-1}}+\alpha_{3} D_{i t} \frac{R E_{i t}}{P_{i t-1}}+\varepsilon_{i t}
$$

\begin{tabular}{|c|c|c|c|}
\hline \multicolumn{4}{|c|}{ Painel A (PREFERENCIAIS) } \\
\hline & Coeficientes & Estatistica-t & P-value \\
\hline$\alpha_{0}$ & 0.0694 & 1.2295 & 0.2223 \\
\hline$\alpha_{1}$ & -0.0874 & -0.9451 & 0.3473 \\
\hline$\alpha_{2}$ & 0.1219 & $1.8389 * * \star$ & 0.0695 \\
\hline$\alpha_{3}$ & -0.5846 & $-2.1400 * *$ & 0.0352 \\
\hline \multicolumn{3}{|c|}{ R-quadrado Ajustado } & 0.1580 \\
\hline \multicolumn{4}{|c|}{ Painel B (ORDINÁRIAS) } \\
\hline & Coeficientes & Estatistica-t & P-value \\
\hline$\alpha_{0}$ & 0.1076 & 2.2671 & 0.0262 \\
\hline$\alpha_{1}$ & 0.1361 & 0.1608 & 0.8727 \\
\hline$\alpha_{2}$ & 0.0972 & $2.6798^{*}$ & 0.0090 \\
\hline$\alpha_{3}$ & 0.0737 & 0.3187 & 0.7508 \\
\hline \multicolumn{3}{|c|}{ R-quadrado Ajustado } & 0.2616 \\
\hline
\end{tabular}

Em que: * **, ***, são estatisticamente significantes ao nível de 1\%,5\% e 10\% respectivamente. 
regressões, observa-se que o lucro líquido, na norma brasileira, é mais oportuno para as ações ordinárias do que para as ações preferenciais. Isso pode estar relacionado com o trabalho de Costa (2005), que constatou que o lucro líquido apresenta maior relevância para os acionistas ordinários, em comparação aos preferenciais. Os acionistas ordinários teriam maior foco na companhia sob sua direção, dado que são eles que possuem direito a voto nas deliberações sociais.

Quanto aos coeficientes que medem o conservadorismo contábil, $\alpha_{1}$ e $\alpha_{3}$, apresentam-se estatisticamente significantes apenas nas ações preferenciais. Todavia, o coeficiente $\alpha_{3}$ apresenta sinal negativo, portanto, não se encontram evidências de reconhecimento assimétrico em ambas as amostras.

Os resultados encontrados corroboram, em parte, a pesquisa de Costa, Lopes e Costa (2006), que evidenciou conservadorismo nas empresas brasileiras com ações na Bovespa. Todavia, sua pesquisa envolve todas as empresas da Bolsa de Valores de São Paulo.

A Tabela 30 apresenta os resultados das regressões estatísticas para o conservadorismo e a oportunidade do lucro contábil segundo as normas contábeis americanas.

A Tabela 3 indica que o lucro líquido, na norma contábil americana, não incorpora significativamente o retorno econômico de junho para ações ordinárias, apesar do coeficiente $\alpha_{2}$ ser positivo apresenta-se como não estatisticamente significante. Para o lucro líquido na norma contábil americana para as ações preferenciais, a significância estatística apresenta um coeficiente a um nível de 5\%.

Quanto aos coeficientes que medem o conservadorismo contábil, $\alpha_{1}$ e $\alpha_{3}$, não se apresentam estatisticamente significantes para a amostra com ações preferenciais, enquanto, para as ações ordinárias, o coeficiente $\alpha_{1}$ apresen- ta-se estatisticamente significante a um nível de $5 \%$. Todavia, o coeficiente $\alpha_{1}$ é positivo, contrariando os resultados esperados pelo modelo.

Sendo assim, não é possível afirmar que o nível de utilização do conservadorismo é maior para as demonstrações com configuração contábil em US GAAP para as empresas pesquisadas.

Esses resultados podem estar relacionados ao trabalho de Tukamoto (2004), que ao investigar se existem diferenças no nível de gerenciamento de resultados entre as companhias que emitiram ADRs e as que não emitiram, não foi possível encontrar nenhuma evidência que revelasse a existência de diferenças na qualidade informacional entre as demonstrações contábeis segundo as normas brasileiras e americanas.

Ao analisar como o lucro contábil incorpora o retorno econômico nas demonstrações em BR GAAP e US GAAP nas empresas pesquisadas, pode-se inferir que o lucro contábil em BR GAAP incorpora o retorno econômico mais significativamente. Isso pode estar relacionado à divulgação dos resultados contábeis pela norma brasileira, que são publicados até abril, ou seja, dois meses antes dos resultados em US GAAP que são publicados em junho. $O$ mercado anteciparia o retorno de junho com a divulgação dos resultados na norma brasileira em abril.

Outro fator seria o de que as empresas utilizadas na amostra possuem controle acionário concentrado, ou seja, os controladores detêm informação privilegiada, podendo conhecer os resultados contábeis em US GAAP antes de sua divulgação.

A Tabela $4 \bullet$ indica que o resíduo da regressão (ajuste aos US GAAP) entre o lucro líquido nas normas contábeis americanas e brasileiras não incorpora significativamente o retorno econômico de junho, em que o coeficiente $\alpha_{2}$, que mede a oportunidade do lucro não é estatisticamente significante.

Tabela 3 Regressões para lucro contábil segundo normas americanas

$$
\frac{L u c_{i t}}{P_{i t-1}}=\alpha_{0}+\alpha_{1} D_{i t}+\alpha_{2} \frac{R E_{i t}}{P_{i t-1}}+\alpha_{3} D_{i t} \frac{R E_{i t}}{P_{i t-1}}+\varepsilon_{i t}
$$

\begin{tabular}{|c|c|c|c|}
\hline \multicolumn{4}{|c|}{ Painel A (PREFERENCIAIS) } \\
\hline & Coeficientes & Estatistica-t & P-value \\
\hline$\alpha_{0}$ & 0.0306 & 0.5080 & 0.6128 \\
\hline$\alpha_{1}$ & 0.0751 & 0.8231 & 0.4128 \\
\hline$\alpha_{2}$ & 0.1854 & $2.1938^{* *}$ & 0.0310 \\
\hline$\alpha_{3}$ & -0.0999 & -0.3921 & 0.6960 \\
\hline \multicolumn{3}{|c|}{ R-quadrado Ajustado } & 0.2034 \\
\hline \multicolumn{4}{|c|}{ Painel B (ORDINÁRIAS) } \\
\hline & Coeficientes & Estatistica-t & P-value \\
\hline$\alpha_{0}$ & 0.0074 & 0.0783 & 0.9378 \\
\hline$\alpha_{1}$ & 0.3705 & $2.2311^{\star *}$ & 0.0285 \\
\hline$\alpha_{2}$ & 0.2008 & 1.4328 & 0.1559 \\
\hline$\alpha_{3}$ & 0.6486 & 1.4924 & 0.1396 \\
\hline \multicolumn{3}{|c|}{ R-quadrado Ajustado } & 0.1035 \\
\hline
\end{tabular}


Tabela 4 || Regressões para ajuste aos US GAAP (resíduo)

$$
\frac{L u c_{i t}}{P_{i t-l}}=\alpha_{0}+\alpha_{1} D_{i t}+\alpha_{2} \frac{R E_{i t}}{P_{i t-l}}+\alpha_{3} D_{i t} \frac{R E_{i t}}{P_{i t-1}}+\varepsilon_{i t}
$$

\begin{tabular}{|c|c|c|c|}
\hline \multicolumn{4}{|c|}{ Painel A (PREFERENCIAIS) } \\
\hline & Coeficientes & Estatistica-t & P-value \\
\hline$\alpha_{0}$ & -0.0298 & -0.6365 & 0.5262 \\
\hline$\alpha_{1}$ & 0.1149 & 1.6190 & 0.1092 \\
\hline$\alpha_{2}$ & 0.0985 & 1.4982 & 0.1378 \\
\hline$\alpha_{3}$ & 0.2924 & 1.4744 & 0.1441 \\
\hline \multicolumn{3}{|c|}{ R-quadrado Ajustado } & 0.0000 \\
\hline \multicolumn{4}{|c|}{ Painel B (ORDINÁRIAS) } \\
\hline & Coeficientes & Estatistica-t & P-value \\
\hline$\alpha_{0}$ & -0.0380 & -0.5721 & 0.5690 \\
\hline$\alpha_{1}$ & 0.0738 & 0.6298 & 0.5308 \\
\hline$\alpha_{2}$ & 0.0529 & 0.5421 & 0.5894 \\
\hline$\alpha_{3}$ & -0.0071 & -0.0236 & 0.9812 \\
\hline \multicolumn{3}{|c|}{ R-quadrado Ajustado } & 0.0000 \\
\hline
\end{tabular}

Os coeficientes que medem o conservadorismo contábil, $\alpha_{1}$ e $\alpha_{3}$, não são estatisticamente significantes para as ações preferenciais e ordinárias, além disso, o poder de explicação da regressão $\left(R^{2}\right)$ ajustado é nulo.

Comparando as amostras de ações com lucro contábil em BR GAAP e lucro contábil em US GAAP, não é possível afirmar que exista um nível maior de utilização do conservadorismo por parte das normas americanas, ou seja, com as evidências encontradas rejeita-se a hipótese de que as demonstrações contábeis em US GAAP são mais conservadoras que as demonstrações contábeis em BR GAAP nas companhias listadas na Bovespa com ADRS negociadas na NYSE.

A segunda hipótese desta pesquisa relata que o lucro contábil em BR GAAP incorpora mais significativamente o retorno econômico (timeliness) de junho do que o lucro contábil em US GAAP incorpora o retorno econômico de abril. De acordo com os resultados apresentados pelas amostras, rejeita-se a hipótese fundamentada. Para as ações preferenciais em US GAAP, o coeficiente que mede a oportunidade do lucro contábil é estatisticamente signifi- cante a um nível de 5\% enquanto, para as ações ordinárias, o coeficiente não é estatisticamente significante. Isso pode ser explicado pelo fato de que o retorno pode estar sendo antecipado quando da divulgação dos resultados em BR GAAP em abril, ou seja, como o acionista controlador divulga os resultados em BR GAAP de abril já se conhece os resultados em US GAAP de junho.

Ao testar a terceira hipótese, pode-se observar que os ajustes aos US GAAP apresentam coeficientes não estatisticamente significantes para a oportunidade da informação contábil e o reconhecimento assimétrico entre boas e más notícias, além disso o poder explicativo da regressão é nulo. Os ajustes aos US GAAP não capturaram o conservadorismo e a oportunidade da informação contábil. $A$ alta concentração acionária pode ser a razão pela qual o modelo não captura o conservadorismo e a oportunidade do lucro. Rejeita-se a terceira hipótese fundamentada, não se pode afirmar que a parcela não explicada pelo lucro contábil em BR GAAP incorpora o retorno econômico de junho e o reconhecimento assimétrico entre boas e más notícias.

\section{CONSIDERAÇÕES FINAIS}

O presente estudo buscou investigar, empiricamente, o nível de utilização do conservadorismo e a oportunidade do lucro nas demonstrações contábeis segundo as normas brasileiras e americanas nas companhias brasileiras que negociaram ADRs. Espera-se que este estudo venha fomentar as pesquisas que investigam o nível de utilização do conservadorismo no mercado acionário brasileiro como um todo gerando evidências sobre o comportamento da informação contábil a fim de auxiliar os investidores e analistas de mercado no processo decisório.
As evidências encontradas não confirmam as hipóteses, portanto não se pode afirmar que exista um nível maior de utilização do conservadorismo por parte das normas americanas, nas empresas brasileiras emissoras de ADRs. Embora estudos internacionais evidenciem a existência de um maior nível de utilização do conservadorismo por parte das normas contábeis americanas, no presente estudo não é possível essa constatação.

Os coeficientes que refletem o reconhecimento assimétrico do retorno econômico pelo lucro contábil não são es- 
tatisticamente significativos para as ações ordinárias. Uma das razões que podem explicar, em parte, a não existência de diferenças na utilização do nível de conservadorismo entre os GAAPs pode estar relacionada ao trabalho de Tukamoto (2004), no qual se encontram evidências de que o nível de gerenciamento dos resultados (earnings management) das empresas brasileiras com ADRs, mesmo em US GAAP, são similares aos de empresas que não possuem.

Os resultados geraram indícios de que o lucro contábil, segundo as normas brasileiras, é mais oportuno que nas normas americanas. Isso pode estar relacionado à divulgação dos resultados contábeis pela norma brasileira, que são publicados até abril, diferentemente dos resultados nas normas americanas, que são publicados em junho. $\mathrm{O}$ mercado pode estar antecipando o retorno de junho com a divulgação dos resultados, nas normas brasileiras, em abril.

Assim, diante dos resultados encontrados pode-se inferir que o conservadorismo contábil para as empresas brasileiras pode não estar no GAAP e sim estar relacionado com instrumentos de governança corporativa e outros fatores.

A não variabilidade de utilização do conservadorismo entre as GAAPs das empresas com ADRs pode estar re- lacionada ao Gerenciamento de Resultados, ou seja, os resultados segundo o GAAP americano não apresentaram um nível de utilização de conservadorismo muito diferente do GAAP brasileiro. Isso pode estar relacionado com o trabalho de Martinez (2001) que encontrou evidências de que as empresas que lançam ADRs promovem Gerenciamento de Resultados para aumentar lucros um ano antes da emissão.

Sugere-se, para novas pesquisas, investigar a utilização do conservadorismo entre as empresas brasileiras emissoras e não emissoras de ADRs, nas empresas que praticam gerenciamento de resultados, em setores específicos da economia, entre empresas brasileiras com maior e menor grau de liquidez e endividamento, bem como a influência da governança corporativa e o impacto dos problemas de agência, através de proxies tais como a forma de remuneração no conservadorismo e na oportunidade da informação contábil. Uma nova linha interessante de pesquisa é a avaliação do nível de conservadorismo pelo modelo de Basu (1997) entre empresas com maiores e menores Market to Book.

\section{Referências}

AKERLOF, G. The market for "lemmons": quality uncertainty and the market mechanism. Quarterly Journal of Economics, v. 84, n. 3, p. 488500, Aug. 1970.

BALL. R. J.; BROWN. An empirical evaluation of accounting icome numbers. Journal of Accounting Research, v. 6, p. 159-178, Autumn 1968.

.; KOTHARI, S. P; ROBIN; A. The effect of international institutional factors on properties of accounting earnings. Journal of Accounting and Economics, v. 29, p. 1-51, 1999.

BASU, S. The conservantism principle and the asymmetic timeliness of earnings. Journal of Accounting and Economics, n. 24, p. 3-37, 1997.

BEAVER, W. H. The information content of earnings announcements. Empirical research in accounting: selected studies, supplement to. Journal of Accounting Research, v. 6, p. 67-92, 1968.

Breusch, T. S.; Pagan, A. R. The lagrange multiplier test and its applications to model specification in econometrics. Review of Economic Studies, 1980.

BUSHMAN, R. M. et al. Financial accounting information, organizational complexity and corporate governance systems. Journal of Accounting and Economics, v. 37, p. 167-201, 2004.

.; PIOTROSKI, J. D. Financial reporting incentives for conservative accounting: The influence of legal and political institutions. Forthcoming Journal of Accounting and Economics, Jan. 2005. Disponível em: <http://papers.ssrn.com/>. Acesso em: 20 abr. 2005.

COSTA, F. M. Ajustes aos US GAAP: estudo empírico sobre sua relevância para empresas brasileiras com ADRS negociados na bolsa de Nova Iorque. 2005. Tese (Doutorado em Controladoria e Contabilidade) - Departamento de Contabilidade e Atuaria da Faculdade de Economia, Administração e Contabilidade da Universidade de São Paulo, São Paulo.

.; LOPES, A. B.; COSTA, A. C. O. Conservadorismo em cinco países da América do Sul. Revista Contabilidade \& Finanças, São Paulo, ano 17, v. 2, n. 41, p. 07-20, maio/ago. 2006.

HAUSMAN, J. Specification tests in econometrics. Econometrica, v. 46, n. 6, Nov. 1978.

HAVERTY, J. L. Are IFRS and U.S. GAAP Converging? some evidence from people's republic of china companies listed on New York stock exchange. In: AMERICAN ACCOUNTING ASSOCIATION MID-ATLANTIC REGION MEETING. Anais... Arlington, Washington DC, 2004.

HENDRIKSEN, E. S.; VAN BREDA, M. Teoria da contabilidade. Tradução Antonio Zoratto Sanvicente. São Paulo: Atlas, 1999.

LA PORTA, R. et al. Law and Finance. The Journal of Political Economy, v. 106, n. 6, p. 1113-1155, 1998.

LEUZ, C. IAS versus U.S. GAAP: information assymetry-based evidence from germany's new market. Journal of Accounting Research, v. 41, n. 3, p. 445-472, June 2003. 
LOPES, A. B. Uma contribuição ao estudo da relevância da informação contábil para o mercado de capitais: o modelo de Ohlson aplicado à BOVESPA. 2001. Tese (Doutorado em Controladoria e Contabilidade) - Departamento de Contabilidade e Atuária, Faculdade de Economia, Administração e Contabilidade, Universidade de São Paulo, São Paulo.

MARTINEZ, A. L. “Gerenciamentọ" dos resultados contábeis: estudo empírico das companhias abertas brasileiras. São Paulo, 2001. Tese (Doutorado em Ciências Contábeis) - Programa de Pós-Graduação em Ciências Contábeis, Departamento de Contabilidade e Atuária, Faculdade de Economia, Administração e Contabilidade da Universidade de São Paulo, São Paulo.

PENMAN, H. S.; ZHANG, X. Accounting conservantism, the quality of earning, and stock returns. Dez.1999. Disponível em: $<$ http://papers. ssrn:com/>. Acesso em: 20 abr. 2005.

POPE, P. F.; WALKER, M. International differences in the timeliness, conservantism and classication of earnings. Journal of Accounting Research, v. 37, p. 503-87, 1999. Supplement.

SARLO NETO, A. A reação dos preços das ações à divulgação dos resultados contábeis: evidências empíricas sobre a capacidade informacional da contabilidade no mercado acionário brasileiro. 2004. Dissertação (Mestrado Profissional em Ciências Contábeis) - Fundação Instituto Capixaba de Pesquisas em Contabilidade, Economia e Finanças, Vitória.

TUKAMOTO, Y. S. Contribuição ao estudo do "gerenciamento" de resultados - uma comparação entre as companhias abertas brasileiras emissoras de ADRs e não emissoras de ADRs. 2004. Dissertação (Mestrado em Controladoria e Contabilidade) - Faculdade de Economia, Administração e Contabilidade da Universidade de São Paulo, São Paulo.

WATTS, R. L. A proposal for research on conservantism. Maio 1993. Disponível em: <http://papers.ssrn.com/>. Acesso em: 20 abr. 2005. Conservantism in accounting part I: explanations and implications. Accounting Horizons, v. 17, n. 3, p. 207-221, Sep. 2003.

\section{NOTA - Endereço dos autores}

\section{FASERRA}

Departamento de Contabilidade e Administração Av. Guarapari, 17 - Valparaíso

Serra-ES

29165-791
Fucape Business School Av. Fernando Ferrari, 1358 - Goiabeiras Vitória - ES

29075-010 